\title{
Patterns of Prescribing Co-Amoxiclav to Children in Ibri Polyclinic, Oman
}

"Weaam S. Al-Yaqoubi and Nadia S. Al-Maqbali

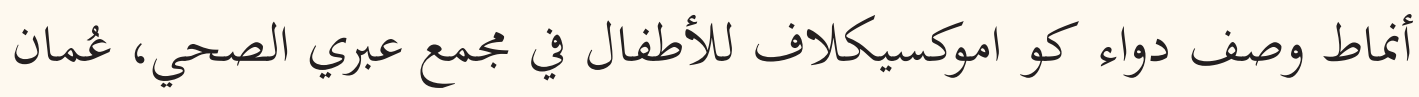

وئام سعيد اليعقوبية ونادية سيف المقبالية

ABSTRACT: Objectives: This study aimed to describe patterns of prescribing co-amoxiclav to children aged $\leq 5$ years at a polyclinic in Oman and to assess level of adherence to the antibiotic prescription guidelines outlined by the Omani Ministry of Health (MOH). Methods: This cross-sectional retrospective study was conducted between June and December 2017 at Ibri Polyclinic (IPC) in Ibri, Oman. A random sample of 399 children aged $\leq 5$ years who were prescribed a suspension of co-amoxiclav over the four winter months of 2016 were included in the study. The children's electronic medical records were reviewed to determine whether the prescription complied with $\mathrm{MOH}$ guidelines. Results: The majority of the children were $2-3$ years old (52.4\%). Overall, $73.9 \%$ of prescriptions were written by general practitioners, while $26.1 \%$ were written by specialists. Co-amoxiclav therapy was the first line of management in $90.5 \%$ of cases, regardless of category of prescriber. Culture tests were ordered in only 43 cases (10.8\%), of which five (11.6\%) were found to be sensitive to the prescribed co-amoxiclav. Conclusion: Unnecessary antibiotics were prescribed to many paediatric patients attending IPC. Strict enforcement of the MOH antibiotic guidelines is needed to reduce irrational or discretionary prescription of this type of antibiotic. Healthcare providers should receive additional training in evidence-based methods of prescribing antibiotics.

Keywords: Antibiotics; Children; Co-Amoxiclav; Inappropriate Prescribing; Antibiotic Resistance; Oman.

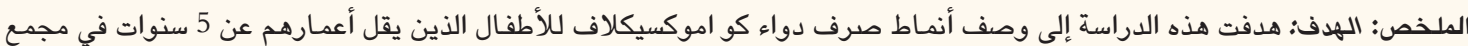

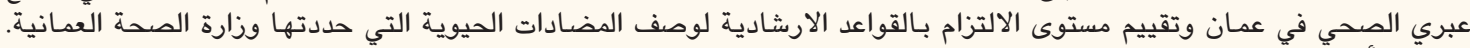

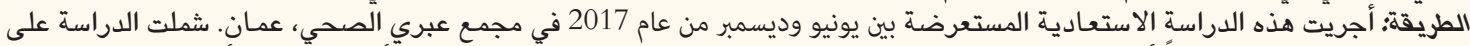

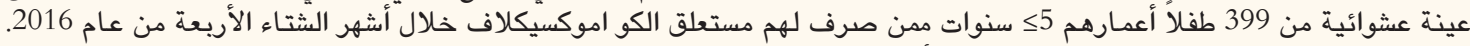

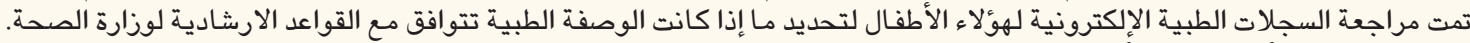

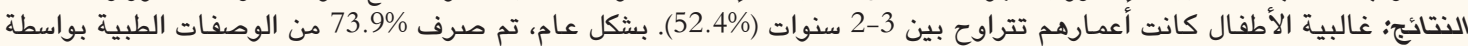

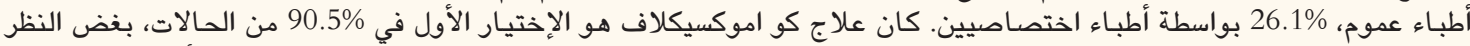

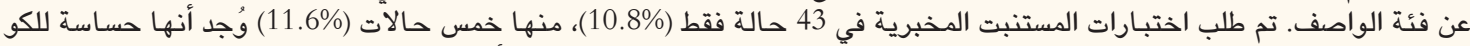

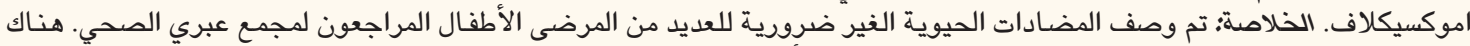

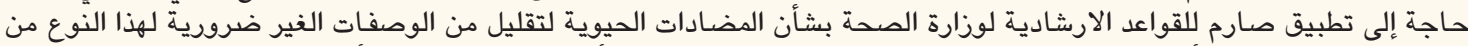

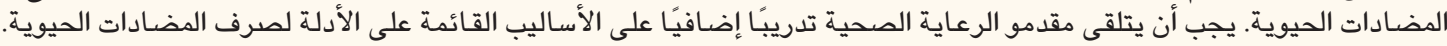

$$
\text { الكلمات المفتاحية: المضادات الحيوية؛ أطفال؛ كو اموكسيكلاف؛ وصف غير مناس لرعاسب؛ مقاومة المضاد الحيوي؛ عمان. }
$$

\section{AdVANCES IN KNOWLEDGE}

The results of the study indicate a high rate of unjustified or irrational paediatric antibiotic prescribing by healthcare practitioners at the facility. These findings provide important data which may inform future research in the fields of pharmacy, paediatrics and rural medical care in Oman.

To the best of the authors' knowledge, this study is the first to evaluate prescribing patterns of a specific antibiotic (co-amoxiclav) to children at a semi-rural primary healthcare facility in Oman.

\section{Application to Patient Care}

The findings of this study may be useful for policymakers and healthcare professionals to more strictly enforce established national guidelines for antibiotic prescribing, in addition to raising awareness among parents regarding the danger of antibiotic misuse among children.

$\mathrm{S}$ INCE THEIR ADVENT IN THE 194OS, RESEARCHERS have warned that the overuse of antibiotics can lead to the proliferation of resistant bacterial strains. ${ }^{1,2}$ Unfortunately, despite the implementation of clear prescription regulations and guidelines, antibiotics are often prescribed as first-line treatment for infections, particularly by primary healthcare physicians. ${ }^{3}$ In particular, general practitioners often 
lack the necessary resources or time to conduct pathological investigations and therefore prescribe paediatric antibiotics as a form of prophylaxis, particularly in cases of upper respiratory tract infection, even though most infections of this type are viral in origin. ${ }^{4}$

In Oman, the Ministry of Health $(\mathrm{MOH})$ requires all physicians to order laboratory investigations and prescribe antibiotics only if warranted and in optimal doses based on the child's age, weight, hepatic and renal function and the severity of the infection; in addition, the prescriber should provide clear and detailed usage and follow-up instructions to all patients. ${ }^{5}$ However, national trends of antibiotic prescription and consumption are still not well-studied. In 2003, the World Health Organisation reported the frequent misuse of antibiotics in primary healthcare centres (PHCs) in Oman. ${ }^{6}$ A later study reported that doctors employed in private healthcare facilities often overprescribed broad-spectrum antibiotics, with similar trends reported in Qatar. ${ }^{7,8}$ Balkhair et al. raised concerns over the increasing prevalence of multidrugresistant organisms observed at a tertiary care hospital in Oman, underlining the need to investigate antibiotic consumption patterns in the country.

Amoxicillin is one of the most popular types of paediatric antibiotics prescribed worldwide and is often administered alongside clavulanic acid, with this combination referred to as co-amoxiclav. ${ }^{10}$ In 2014, a study of 499 Omani children under 12 years of age in Muscat, the capital city of Oman, found that most co-amoxiclav prescriptions were issued to children aged 0-6 years. ${ }^{11}$ In 2017, co-amoxiclav was the first and second most prescribed antibiotic to paediatric inpatients and outpatients, respectively. ${ }^{12}$ In Ibri, a semi-rural town in Al Dhahirah Governorate, antibiotics comprised $24.7 \%$ of all drugs prescribed at the local polyclinic in 2016, the second highest rate among all PHCs in the governorate. ${ }^{13}$

To the best of the authors' knowledge, no study has yet been conducted to evaluate co-amoxiclav prescribing patterns among children in PHCs located in rural or semi-rural regions of Oman. Accordingly, the present study sought to describe patterns of prescribing a co-amoxiclav suspension to children aged $\leq 5$ years at a polyclinic in Ibri and to assess whether such prescriptions adhered to the $\mathrm{MOH}$ antibiotic prescription guidelines.

\section{Methods}

This retrospective cross-sectional study was conducted at the Ibri Polyclinic (IPC) between June and December
2017. The target population included children aged $\leq 5$ years of any nationality who had attended the general practice, paediatric, dermatology and dental clinics at IPC during the winter months of 2016 (January, February, November and December) and had been prescribed a suspension of co-amoxiclav consisting of $125 \mathrm{mg}$ of amoxicillin and $31 \mathrm{mg}$ of clavulanic acid (Augmentin ${ }^{\circledR}$, GlaxoSmithKline PLC, Brentford, UK).

In mid-2016, there was a total of 393,625 children aged $0-4$ years of both genders and all nationalities in Oman. ${ }^{14}$ As the targeted population size was greater than 10,000, the following formula was used to calculate the necessary sample size: ${ }^{15}$

$$
N=\frac{\mathrm{z}^{2} \times \mathrm{p} \times(1-\mathrm{p})}{\mathrm{d}^{2}} \quad[\text { Equation } 1]
$$

Based on the above formula, the minimum sample size was calculated to be 384. However, this was increased to 400 to compensate for any incomplete records. Children were randomly selected for inclusion in the study by using web-based random number generator software to select specific records from the clinic's electronic medical records system. One incomplete record was found and excluded, leading to the inclusion of 399 children in the final analysis.

Data were retrieved from the children's electronic medical records. Specific information was collected from the system including the child's age, weight and body temperature; dose, frequency and duration of the prescription; documented indications for the prescription; whether a culture was taken and, if so, its result; follow-up visit advice; and whether the prescriber was a specialist (i.e. a paediatric, dermatology or dental specialist) or a general practitioner. Subsequently, this information was used to determine whether the prescription adhered to the $\mathrm{MOH}$ antibiotic guidelines. ${ }^{5}$

Data analysis was performed using the Statistical Package for the Social Sciences (SPSS), Version 23.0 (IBM Corp., Armonk, New York, USA). Descriptive statistics were calculated, including percentages, means and standard deviations. A paired samples t-test was used to determine differences between the prescribed dose and the ideal dose. In addition, an inferential analysis using Pearson's Chi-squared test was conducted to assess correlations. A $P$ value of $<0.050$ was considered statistically significant.

Ethical approval for this study was obtained from the Research and Studies Committee of the Directorate General of Health Services, $\mathrm{MOH}$, Al-Dhahirah Governorate. The privacy and confidentiality of the collected data was maintained at all times. 


\section{Results}

Of the 399 children included in the study, 375 (94\%) were Omani and 24 (6\%) were expatriates of various nationalities. The majority were male $(n=263$; $65.9 \%)$. Children aged $2-3$ years formed more than half $(\mathrm{n}=209 ; 52.4 \%)$ of the participants [Table 1]. Approximately three-quarters $(n=295 ; 73.9 \%)$ of the prescriptions were written by general practitioners, while the remaining 104 prescriptions $(26.1 \%)$ were written by specialists. The vast majority $(\mathrm{n}=351 ; 88 \%)$ of the prescriptions were for upper respiratory tract infections. Most children ( $\mathrm{n}=279 ; 69.9 \%$ ) did not receive any follow-up advice.

Culture tests were ordered in only 43 cases (10.8\%). Specialists were more than twice as likely to order culture tests compared to general practitioners (18.3\% versus $8.1 \% ; P=0.005$ ) [Table 2]. Among the 43 cultures taken, only five $(11.6 \%)$ were found to be sensitive to co-amoxiclav [Table 3]. Nevertheless, co-amoxiclav was prescribed as the first line of management in 361 cases (90.5\%). There was no significant difference between general practitioners and specialists in the use of co-amoxiclav as first-line therapy (90.2\% versus 91.3\%; $P>0.050$ ) [Table 4].

A paired samples t-test revealed no significant difference between mean prescribed dose and mean recommended dose according to body weight (5.90 \pm 1.69 versus $6.01 \pm 1.70 \mathrm{~mL} ; P=0.386$ ). In addition, specialists were significantly more likely to schedule follow-up visits for their patients compared to general practitioners (35.6\% versus $27.8 \%$; $r=0.213$; $P<0.010$ ).

\section{Discussion}

Antibiotic therapy carries greater risks for neonates and young children compared to adults. ${ }^{6}$ In particular, there is the possibility of kidney damage due to drug toxicity as the children's immature elimination systems may not be able to excrete the antibiotic remnants effectively, sometimes leading to organ failure. Moreover, recent research indicates that the administration of antibiotics at an early age may damage the paediatric microbiome, resulting in longterm psychophysiological consequences. ${ }^{17,18}$ Finally, the increasing prevalence of resistant bacteria renders traditional antibiotics less effective. ${ }^{3}$

According to a study from the USA, paediatric antibiotic use declined sharply between 2000-2010 and then plateaued. ${ }^{19}$ However, paediatric antibiotic prescribing trends in countries with emerging economies such as Oman are not clear. Worldwide, it appears that general physicians prescribe more
Table 1: Age distribution of children prescribed co-amoxiclav at a polyclinic in Ibri, Oman $(\mathrm{N}=399)$

$\begin{array}{lc}\text { Age in years } & \mathbf{n}(\%) \\ <1 & 2(0.5) \\ 1 & 41(10.3) \\ 2 & 115(28.8) \\ 3 & 94(23.6) \\ 4 & 70(17.5) \\ 5 & 77(19.3)\end{array}$

Table 2: Frequency of laboratory cultures taken according to category of prescriber among children prescribed coamoxiclav at a polyclinic in Ibri, Oman ( $\mathrm{N}=399)$

$\begin{array}{lccc}\text { Prescriber category } & \begin{array}{c}\text { Laboratory cultures, } \\ \mathbf{n}(\%)\end{array} & P \text { value } \\ & \text { Not taken } & \text { Taken } & \\ \begin{array}{l}\text { General practitioner } \\ (\mathrm{n}=295)\end{array} & 271(91.9) & 24(8.1) & \\ \text { Specialist }(\mathrm{n}=104) & 85(81.7) & 19(18.3) & \end{array}$

Table 3: Types of pathogens identified and antibiotic sensitivity in cultures taken from children prescribed co-amoxiclav at a polyclinic in Ibri, Oman $(\mathrm{N}=43)$

$\begin{array}{ll}\text { Variable } & \text { Culture, } \mathbf{n}(\%) \\ \text { Type of pathogen } & \\ \text { Bacterial } & 14(32.6) \\ \text { Normal flora } & 12(27.9) \\ \text { Unspecified } & 12(27.9) \\ \text { Viral } & 5(11.6) \\ \text { Sensitivity to co-amoxiclav } & \\ \text { Sensitive } & 5(11.6) \\ \text { Not sensitive } & 38(88.4)\end{array}$

Table 4: Line of co-amoxiclav management according to category of prescriber among children prescribed co-amoxiclav at a polyclinic in Ibri, Oman $(\mathrm{N}=399)$

\begin{tabular}{|c|c|c|c|}
\hline \multirow[t]{2}{*}{ Prescriber category } & \multicolumn{2}{|c|}{$\begin{array}{l}\text { Line of management, } \\
\mathrm{n}(\%)\end{array}$} & \multirow[t]{2}{*}{$P$ value } \\
\hline & First & Second & \\
\hline $\begin{array}{l}\text { General practitioner } \\
(\mathrm{n}=295)\end{array}$ & $266(90.2)$ & $29(9.8)$ & \multirow{2}{*}{$>0.050$} \\
\hline Specialist $(\mathrm{n}=104)$ & 95 (91.3) & $9(8.7)$ & \\
\hline
\end{tabular}

antibiotics compared to specialists, particularly those employed in emergency out-of-hours clinics. ${ }^{20,21}$ The results of the current study support this trend, with $73.9 \%$ of co-amoxiclav prescriptions for children 
having been written by general practitioners, although the national $\mathrm{MOH}$ antimicrobial guidelines limit the choice of antibiotics available for prescription by general practitioners. ${ }^{5}$ Ncube et al. reported similar trends in a study of general medical practitioners in South Africa. ${ }^{22}$

Research suggests that several behavioural factors may be associated with the tendency to overprescribe antibiotics among physicians. ${ }^{23}$ These factors include the desire to meet patient expectations or succumbing to patient pressure; time constraints, particularly for general physicians working in busy outpatient clinics; the concept of 'decision fatigue' in which an individual's capacity to make decisions becomes limited after repeated decision-making activities; diagnostic uncertainty; and externalising responsibility in the belief that other doctors would also prescribe antibiotics. $^{23}$ In Western countries, doctors also experience additional pressure to prescribe antibiotics as a result of the risk of medical malpractice lawsuits. ${ }^{24}$ As yet, no data from Oman are available to shed light on the behavioural factors which might influence physicians to prescribe antibiotics. Studies on this topic would help achieve a better understanding of and potentially mitigate such pressures on doctors in Oman.

The empirical prescription of antibiotics is sometimes warranted based on clinical evidence; however, in most cases, antibiotic therapy should be initiated only based on the results of bacterial cultures. ${ }^{25}$ In Oman, the $\mathrm{MOH}$ guidelines specify the need for culture testing to ensure that patients receive rational and targeted therapy. ${ }^{5}$ In the present study, culture tests were conducted in only $10.8 \%$ of cases, of which only $32.6 \%$ had bacterial infections and only $11.6 \%$ were sensitive to the antibiotic prescribed. However, it should be acknowledged that the reliability of culture tests cannot be taken for granted. A retrospective study by El-Naggari et al. found the incidence of falsepositive results due to sample contamination to be as high as $46.2 \%$ among 344 positive blood cultures obtained at a tertiary hospital in Oman. ${ }^{26}$

In the current study, the majority of paediatric co-amoxiclav prescriptions were issued as the first line of management for upper respiratory tract infections. This practice appears contrary to the national $\mathrm{MOH}$ antibiotic guidelines. ${ }^{5}$ According to the National Institute of Health and Care Excellence (NICE) in the UK, most instances of acute sore throatwhether bacterial or viral in aetiology-tend to be self-limiting and usually resolve within seven days without antibiotics. ${ }^{27}$ In addition, up to $90 \%$ of cases of acute bronchitis are viral and usually resolve without treatment. ${ }^{28}$ Therefore, it is essential that parents in Oman be educated regarding the differences between bacterial and viral infections so that they do not seek unnecessary therapy for children with self-limiting conditions. These individuals should also be informed of the long-term health risks associated with the misuse of paediatric antibiotics.

The mean dose of co-amoxiclav suspension prescribed by IPC healthcare practitioners in the present study did not differ significantly from the ideal dose outlined in the $\mathrm{MOH}$ guidelines. Doses were calculated according to weight for patients with mild to moderate diseases, with the dosage doubled for severe conditions such as acute otitis media. ${ }^{5}$ Specifically, the dosage of co-amoxiclav is calculated at $0.25 \mathrm{~mL} / \mathrm{kg}$ administered every 8 hours and is doubled for severe infections. This calculation is based on recommendations from the British National Formulary. ${ }^{29}$

The findings of the present study should be considered in light of certain limitations. First, the target population was confined to children attending a single rural healthcare centre in Oman. As such, larger samples taken from multiple healthcare centres in Oman could have enhanced the generalisability of the study. Second, the data collection period was restricted to the four winter months of 2016 instead of the full year. In future, a more detailed study that addresses the above limitations is recommended.

\section{Conclusion}

There was considerable over-prescription of coamoxiclav to children at a semi-rural clinic in Oman, indicating that the prescribers did not adhere to the existing $\mathrm{MOH}$ guidelines on paediatric antibiotic use. As such, these guidelines need to be implemented more strictly, with a greater degree of accountability. Continuing medical education activities on evidencebased methods of prescribing antibiotics are needed for healthcare practitioners. In addition, parents should be educated regarding the long-term health risks posed by the misuse of antibiotics in children. Finally, the $\mathrm{MOH}$ should consider publishing educational leaflets on the dangers of antibiotic misuse for distribution at all hospitals, clinics and pharmacies nationwide.

\section{CONFLICT OF INTEREST}

The authors declare no conflicts of interest.

\section{FUNDING}

No funding was received for this study. 


\section{References}

1. Aminov RI. A brief history of the antibiotic era: Lessons learned and challenges for the future. Front Microbiol 2010; 1:134. https://doi.org/10.3389/fmicb.2010.00134.

2. Dietert R. The human superorganism: How the microbiome is revolutionizing the pursuit of a healthy life, 1st ed. London, UK: Penguin Books, 2016

3. Llor C, Bjerrum L. Antimicrobial resistance: Risk associated with antibiotic overuse and initiatives to reduce the problem. Ther Adv Drug Saf 2014; 5:229-41. https://doi.org/10.1177/204 2098614554919.

4. Fair RJ, Tor Y. Antibiotics and bacterial resistance in the 21st century. Perspect Medicin Chem 2014; 6:25-64. https://doi. org/10.4137/PMC.S14459.

5. Directorate General of Rational Use of Medicine, Ministry of Health. Oman national formulary for Ministry of Health institutions: Third edition 2016. From: www.moh.gov.om/ documents $/ 16569 / 0 / O N F+2016+-$ for $+E+$ Health +Portal. pdf/3f224743-563e-4640-85c1-fe46abe3db93 Accessed: Apr 2020

6. World Health Organization. Annual report 2002: Essential drugs and medicines policy - Supporting countries to close the access gap. From: https://apps.who.int/iris/handle/10665/67912 Accessed: Apr 2020.

7. Kutty N. Treating children without antibiotics in primary healthcare. Oman Med J 2011; 26:303-5. https://doi.org/10.5001/omj.2011.77.

8. Shaikhan F, Rawaf S, Majeed A, Hassounah S. Knowledge, attitude, perception and practice regarding antimicrobial use in upper respiratory tract infections in Qatar: A systematic review. JRSM Open 2018; 9:2054270418774971. https://doi. org/10.1177/2054270418774971.

9. Balkhair A, Al-Farsi YM, Al-Muharrmi Z, Al-Rashdi R, Al-Jabri M, Neilson F, et al. Epidemiology of multi-drug resistant organisms in a teaching hospital in Oman: A one-year hospitalbased study. ScientificWorldJournal 2014: 2014;157102. https:// doi.org/10.1155/2014/157102

10. Li G, Jackson C, Bielicki J, Ellis S, Hsia Y, Sharland M. Global sales of oral antibiotics formulated for children. Bull World Health Organ 2020; 98:458-66. https://doi.org/10.2471/BLT.19.235309.

11. Al-Balushi K, Al-Ghafri F, Al-Sawafi F, Al-Zakwani I. Antibiotic prescribing trends in an Omani paediatric population. Sultan Qaboos Univ Med J 2014; 14:e495-9.

12. Oman Ministry of Health. Oman antimicrobial resistance surveillance system: Annual report - 2017. From: www.moh. gov.om/documents/236878/0/OMASS+2017/ca052ace-691a1919-7b96-41f79539660a Accessed: Apr 2020

13. Ministry of Health. Statistics register (Al Dhahira) for the year 2016. Oman: $\mathrm{MOH}$.

14. Oman Ministry of Health. Annual health report 2016. From: www.moh.gov.om/documents/274609/1624207/\%D9\%85\%D9 \%82\%D8\%AF\%D9\%85\%D8\%A9/d7a973be-edf6-48c5-ac7a16cc5f65aeb8 Accessed: Apr 2020.

15. Lewis J. Sample size estimation and use of substitute audiences. From: https://www.researchgate.net/publication/228579923 Sample_size_estimation_and_use_of_substitute_audiences Accessed: Apr 2020.
16. Edlin RS, Copp HL. Antibiotic resistance in pediatric urology. Ther Adv Urol 2014; 6:54-61. https://doi.org/10.1177/17562 87213511508 .

17. Oldenburg CE, Sié A, Coulibaly B, Ouermi L, Dah C, Tapsoba C, et al. Effect of commonly used pediatric antibiotics on gut microbial diversity in preschool children in Burkina Faso: A randomized clinical trial. Open Forum Infect Dis 2018; 5:ofy289. https://doi.org/10.1093/ofid/ofy289.

18. Deans E. Microbiome and mental health in the modern environment. J Physiol Anthropol 2016; 36:1. https://doi.org/10.1186/ s40101-016-0101-y.

19. Vaz LE, Kleinman KP, Raebel MA, Nordin JD, Lakoma MD, Dutta-Linn MM, et al. Recent trends in outpatient antibiotic use in children. Pediatrics 2014; 133:375-85. https://doi. org/10.1542/peds.2013-2903.

20. Pulcini C, Lions C, Ventelou B, Verger P. Indicators show differences in antibiotic use between general practitioners and paediatricians. Eur J Clin Microbiol Infect Dis 2013; 32:929-35. https://doi.org/10.1007/s10096-013-1828-6.

21. Huibers L, Moth G, Christensen MB, Vedsted P. Antibiotic prescribing patterns in out-of-hours primary care: A populationbased descriptive study. Scand J Prim Health Care 2014; 32:200-7. https://doi.org/10.3109/02813432.2014.972067.

22. Ncube NB, Solanki GC, Kredo T, Lalloo R. Antibiotic prescription patterns of South African general medical practitioners for treatment of acute bronchitis. S Afr Med J 2017; 107:119-22. https://doi.org/10.7196/SAMJ.2017.v107i2.11276.

23. Talkington K, Hyun D, Zetts R, Thomas J. What drives inappropriate antibiotic use in outpatient care? Behavioral science strategies can help improve antibiotic prescribing habits. From: www.pewtrusts.org/en/research-and-analysis/ issue-briefs/2017/06/what-drives-inappropriate-antibioticuse-in-outpatient-care Accessed: Apr 2020.

24. Fletcher-Lartey S, Yee M, Gaarslev C, Khan R. Why do general practitioners prescribe antibiotics for upper respiratory tract infections to meet patient expectations: A mixed methods study. BMJ Open 2016; 6:e012244. https://doi.org/10.1136/ bmjopen-2016-012244.

25. Harris AM, Bramley AM, Jain S, Arnold SR, Ampofo K, Self WH, et al. Influence of antibiotics on the detection of bacteria by culture-based and culture-independent diagnostic tests in patients hospitalized with community-acquired pneumonia. Open Forum Infect Dis 2017; 4:oxf014. https://doi.org/10.1093/ ofid/ofx014.

26. El-Naggari MA, Al-Mulaabed SW, Al-Muharrmi Z, Mani R, Abdelrahim R, Abdwani R. Blood culture contaminants in a paediatric population: Retrospective study from a tertiary hospital in Oman. Sultan Qaboos Univ Med J 2017; 17:e202-8. https://doi.org/10.18295/squmj.2016.17.02.011.

27. National Institute for Health and Care Excellence. Sore throat (acute): Antimicrobial prescribing NICE guideline [NG84]. From: www.nice.org.uk/guidance/ng84 Accessed: Apr 2020

28. Albert RH. Diagnosis and treatment of acute bronchitis. Am Fam Physician 2010; 82:1345-50.

29. British Joint Formulary Committee. British National Formulary (BNF) 76. London, UK: British Medical Association and Royal Pharmaceutical 